\title{
Alternative pathways as mechanism for the negative effects associated with overexpression of superoxide dismutase
}

\author{
Axel Kowald*, Hans Lehrach, Edda Klipp \\ Kinetic Modelling Group, Max Planck Institute for Molecular Genetics, Ihnestr. 73, 14195 Berlin, Germany
}

Received 28 February 2005; received in revised form 27 June 2005; accepted 28 June 2005

\begin{abstract}
One of the most important antioxidant enzymes is superoxide dismutase (SOD), which catalyses the dismutation of superoxide radicals to hydrogen peroxide. The enzyme plays an important role in diseases like trisomy 21 and also in theories of the mechanisms of aging. But instead of being beneficial, intensified oxidative stress is associated with the increased expression of SOD and also studies on bacteria and transgenic animals show that high levels of SOD actually lead to increased lipid peroxidation and hypersensitivity to oxidative stress. Using mathematical models we investigate the question how overexpression of SOD can lead to increased oxidative stress, although it is an antioxidant enzyme. We consider the following possibilities that have been proposed in the literature: (i) Reaction of $\mathrm{H}_{2} \mathrm{O}_{2}$ with $\mathrm{CuZnSOD}$ leading to hydroxyl radical formation. (ii) Superoxide radicals might reduce membrane damage by acting as radical chain breaker. (iii) While detoxifying superoxide radicals SOD cycles between a reduced and oxidized state. At low superoxide levels the intermediates might interact with other redox partners and increase the superoxide reductase (SOR) activity of SOD. This short-circuiting of the SOD cycle could lead to an increased hydrogen peroxide production.

We find that only one of the proposed mechanisms is under certain circumstances able to explain the increased oxidative stress caused by SOD. But furthermore we identified an additional mechanism that is of more general nature and might be a common basis for the experimental findings. We call it the alternative pathway mechanism.
\end{abstract}

(C) 2005 Elsevier Ltd. All rights reserved.

Keywords: Anti-oxidants; Aging; Free radicals; Transgenics

\section{Introduction}

While most eukaryotes rely on oxygen for their energy production by oxidative phosphorylation, oxygen is usually lethal at concentrations above $40 \%$ (Joenje, 1989). It is thought that not oxygen itself but its reactive derivatives like the superoxide radical $\left(\mathrm{O}_{2}{ }^{-}\right)$, hydrogen peroxide $\left(\mathrm{H}_{2} \mathrm{O}_{2}\right)$, the hydroxyl radical $\left(\mathrm{HO}^{\bullet}\right)$ and singlet oxygen $\left({ }^{1} \mathrm{O}_{2}\right)$ are the damaging agents. Oxygen radicals cannot only damage proteins, membranes and DNA (Pryor, 1973; Wolff et al., 1986; Davies, 1987; Mene-

\footnotetext{
*Corresponding author. Tel.: + 493080409317 ; fax: +493080409322 .

E-mail address: kowald@molgen.mpg.de (A. Kowald).
}

ghini, 1988), but they have also been implicated in the aging process (Harman, 1956, 1981; Fleming et al., 1981). The superoxide radical is produced by several enzymes like xanthine oxidase, indoleamine dioxygenase, tryptophan dioxygenase and aldehyde oxidase (Halliwell and Gutteridge, 1989), but the most important sources of $\mathrm{O}_{2}^{-}$- in vivo are the electron transport chain of mitochondria and the endoplasmatic reticulum. The generation of superoxide radicals by mitochondria is estimated to be $1-2 \%$ of the cellular oxygen uptake (Joenje, 1989; Chance et al., 1979). To counteract the threat posed by oxidative stress cells have developed an impressive arsenal of enzymatic and low molecular weight compounds to remove and detoxify free oxygen radicals. The most important enzymes involved in this 
process are superoxide dismutase (SOD) which catalyses the dismutation of superoxide radicals to hydrogen peroxide (McCord and Fridovich, 1969) and catalase as well as glutathione peroxidase (GPX) which both convert hydrogen peroxide into water. Several forms of SOD exist which can be classified by their metal cofactor. The copper/zinc enzyme (CuZnSOD) is found in the cytosol of eukaryotes, in the chloroplasts of some plants and as a special extracellular version (EC-SOD). Recently, CuZnSOD has also been detected in many bacteria. Manganese SOD (MnSOD) exists in prokaryotes and eukaryotes, but in the latter appears exclusively in the mitochondrial matrix. An iron containing form (FeSOD) is constitutively expressed in prokaryotes and some chloroplasts (for review, see Bannister et al., 1987) and recently a dismutase with nickel as cofactor (NiSOD) has been described in Streptomyces and cyanobacteria (Youn et al., 1996; Palenik et al., 2003).

Since SOD catalyses the first step in this chain of important antioxidant reactions it has been tempting to speculate that increasing the concentration of SOD might confer additional resistance to oxidative stress or prolong lifespan. Many studies have been performed to investigate this idea, but surprisingly most of them showed that high levels of SOD have deleterious effects. Groner et al. (1986) could show that transfected cells producing high levels of CuZnSOD suffer from increased lipid peroxidation. Also other cell culture experiments found that overexpression of $\mathrm{CuZnSOD}$ leads to hypersensitivity to oxidative stress which could be counterbalanced by increased catalase (Amstad et al., 1991) or GPX levels (Amstad et al., 1994). Using transgenic animals it could be shown that this negative effect is also present at the organismic level. Transgenic Drosophila melanogaster with elevated CuZnSOD activity exhibited heavy mortality during development (Orr and Sohal, 1993) and died during the process of eclosion (Reveillaud et al., 1991). Increased lipid peroxidation is also associated with Down syndrome (DS) (Brooksbank and Balazs, 1984) a frequent human genetic disorder with three copies of chromosome 21 (trisomy 21). The gene for CuZnSOD is on chromosome 21 and the increased oxidative stress seen in those patients is thought to be caused by the elevated CuZnSOD activity (Sinet, 1982). Two groups produced mice transgenic for CuZnSOD as an animal model for DS and both found severe impairments like lipid peroxidation, diminished prostaglandin synthesis and serotonin uptake and abnormal neuromuscular junctions (Avraham et al., 1988; Schickler et al., 1989; Minc-Golomb et al., 1991; Ceballos-Picot et al., 1991, 1992). Finally, also bacteria overexpressing FeSOD or MnSOD showed increased sensitivity to paraquat (Bloch and Ausubel, 1986; Scott et al., 1987; Siwecki and Brown, 1990). Some studies (for instance Chan et al., 1998; Keller et al., 1998), did report beneficial effects of overexpressing SOD. But even in these cases increased oxidative stress is often associated with the elevated SOD levels (Keller et al., 1998).

The most popular interpretation brought forward to explain the observed detrimental effects is that increased levels of SOD directly lead to an increase in the steadystate concentration of hydrogen peroxide, the product of the dismutation reaction (Groner et al., 1986, 1990; Scott et al., 1987; Avraham et al., 1988; Yarom et al., 1988; Kelner and Bagnell, 1990; Seto et al., 1990; Amstad et al., 1991, 1994; Ceballos-Picot et al., 1991; Minc-Golomb et al., 1991; Reveillaud et al., 1991; Mao et al., 1993; de Haan et al., 1995; Zhong et al., 1996; Keller et al., 1998; Schwartz and Coyle, 1998).

However, this simple scenario cannot be correct if we only consider the core reaction of SOD. The important point is that under steady-state conditions the rate of superoxide generation has to be identical to the rate of superoxide removal. That means if we only consider the simple chain of reactions $\rightarrow \mathrm{O}_{2}^{\cdot} \stackrel{\text { SOD }}{\longrightarrow} \mathrm{H}_{2} \mathrm{O}_{2} \stackrel{\text { cat/GPX }}{\longrightarrow} \mathrm{H}_{2} \mathrm{O}$, it can easily be shown that the amount of SOD controls the steady-state concentration of superoxide, but does not at all influence the hydrogen peroxide steady-state level. The following two equations describe such a system:

$$
\begin{aligned}
& \frac{\mathrm{dO}_{2}^{\bullet-}}{\mathrm{d} t}=c_{1}-c_{2} \cdot \mathrm{SOD} \cdot \mathrm{O}_{2}^{\bullet-} \\
& \frac{\mathrm{dH}_{2} \mathrm{O}_{2}}{\mathrm{~d} t}=c_{2} \cdot \mathrm{SOD} \cdot \mathrm{O}_{2}^{\cdot-}-c_{3} \cdot \mathrm{cat} \cdot \mathrm{H}_{2} \mathrm{O}_{2}
\end{aligned}
$$

Solving this system for steady-state conditions gives us $\mathrm{O}_{2, \mathrm{ss}}^{\bullet}=c_{1} / c_{2} \cdot \mathrm{SOD}$ and $\mathrm{H}_{2} \mathrm{O}_{2, \mathrm{ss}}=c_{1} / c_{3} \cdot$ cat. The hydrogen peroxide level is completely independent of SOD. Only the enzyme that removes $\mathrm{H}_{2} \mathrm{O}_{2}$ can influence its concentration. This result is independent of the reaction law used. It also holds if we had used a Michaelis Menten kinetics instead of the simpler mass action law or if we had assumed a reversible instead of an irreversible kinetics for the reactions for SOD and cat/GPX.

If high levels of SOD cannot directly lead to increased oxidative stress, how else might the observed negative effects be mediated? Obviously, the simple reaction described above, is not sufficient to explain the observed phenomena. It seems necessary to include additional chemical reactions to understand this counter intuitive behaviour and find explanations how SOD can exert an influence on hydrogen peroxide or other molecular species conferring oxidative stress.

In the present study we therefore investigated three other ideas that have been proposed as possible explanations. We found that only one of these mechanisms operates as expected under certain conditions. However, using model simulations we discovered a new, more general, mechanism that might account for the 
observations. We call this the Alternative Pathway mechanism.

\section{Model description}

Three further ideas have been proposed in the literature to explain increased oxidative stress associated with increased levels of SOD. Our intention is to construct a model that is complex enough to represent all these ideas and to formalize this model using differential equations. Computer simulations will then test if the ideas are consistent and show possible interactions. The ideas that are described by the model are as follows:

1. The mechanism of SOD is based on a cyclic process during which the catalytic metal centre is reduced and re-oxidized. Exemplified for CuZnSOD the two reactions of this cycle are as follows (the numbers above the oxygen species indicate the oxidation state):

$$
\begin{aligned}
& \mathrm{Cu}(\mathrm{II}) \mathrm{ZnSOD}+\mathrm{O}_{2}^{\circ} \stackrel{0}{\stackrel{-}{-1}} \stackrel{\text { oxidation }}{\longrightarrow} \mathrm{Cu}(\mathrm{I}) \mathrm{ZnSOD}+\stackrel{0 / 0}{\mathrm{O}_{2}} \\
& \mathrm{Cu}(\mathrm{I}) \mathrm{ZnSOD}+\mathrm{O}_{2}^{\circ--}+2 \mathrm{H}^{+} \stackrel{\text { reduction }}{\longrightarrow} \mathrm{Cu}(\mathrm{II}) \mathrm{ZnSOD}+\mathrm{H}_{2} \mathrm{O}_{2}
\end{aligned}
$$

If an electron donor other than superoxide would reduce the $\mathrm{Cu}(\mathrm{II})$ to $\mathrm{Cu}(\mathrm{I})$, SOD would act as a superoxide reductase (SOR). And if superoxide would be replaced as electron acceptor in re-oxidizing $\mathrm{Cu}(\mathrm{I})$ to $\mathrm{Cu}(\mathrm{II})$, the enzyme would act as superoxide oxidase (SOO) (Liochev and Fridovich, 2000; Offer et al., 2000). The important difference is that under normal conditions one molecule of hydrogen peroxide is generated for two molecules of superoxide, while a SOR produces one $\mathrm{H}_{2} \mathrm{O}_{2}$ for every $\mathrm{O}_{2}^{\bullet-}$ consumed.

2. Superoxide can initiate lipid peroxidation via its conjugated base, the perhydroxyl radical $\mathrm{HO}_{2}^{\bullet}$ (superoxide itself is not reactive enough (Halliwell and Gutteridge, 1999)). However, it has also been suggested that superoxide radicals can actually serve as terminator of lipid peroxidation by reacting with lipid peroxyl radicals to yield lipid hydroperoxides: $\mathrm{LOO}^{\circ}+\mathrm{O}_{2}^{\bullet-}+\mathrm{H}^{+} \rightarrow \mathrm{LOOH}+\mathrm{O}_{2}$ (Nelson et al., 1994). Over-scavenging of $\mathrm{O}_{2}^{\bullet-}$ by large amounts of SOD could then lead to increased net lipid peroxidation by increasing the chain length.

3. It has been known for many years that in addition to its SOD activity CuZnSOD has also a peroxidase function (Hodgson and Fridovich, 1975). Although the details are still unresolved more recent work indicates that by reacting with $\mathrm{H}_{2} \mathrm{O}_{2}$ the enzyme can act as free radical generator (Yim et al., 1990, 1993; Goss et al., 1999; Sankarapandi and Zweier, 1999).
This way increased CuZnSOD might lead to increased oxidative stress.

Typically the concentrations of radicals and reactive oxygen species (ROS) are very low (only a few molecules per cell) so that stochastic effects become apparent. If it can be expected that these effects are relevant for the behaviour of the described system, a stochastic modelling approach should be chosen. For instance, this would be the case if signal transduction pathways or the effects of transcription factors are modelled. There it makes a large difference if zero or one molecule is present, since a single copy can serve as trigger to start a complex response. For low levels of radicals, however, stochastic modelling does not seem necessary, since radicals do not act as such triggers (at least not in the reactions included in the model).

\subsection{Overview of the model}

Fig. 1 gives an overview of the model reactions that incorporate the above points. Labels $\mathrm{v}_{x}$ denote the different reactions and for enzymatically catalysed reactions $\left(\mathrm{v}_{6}\right.$ and $\left.\mathrm{v}_{7}\right)$ the participating enzyme is

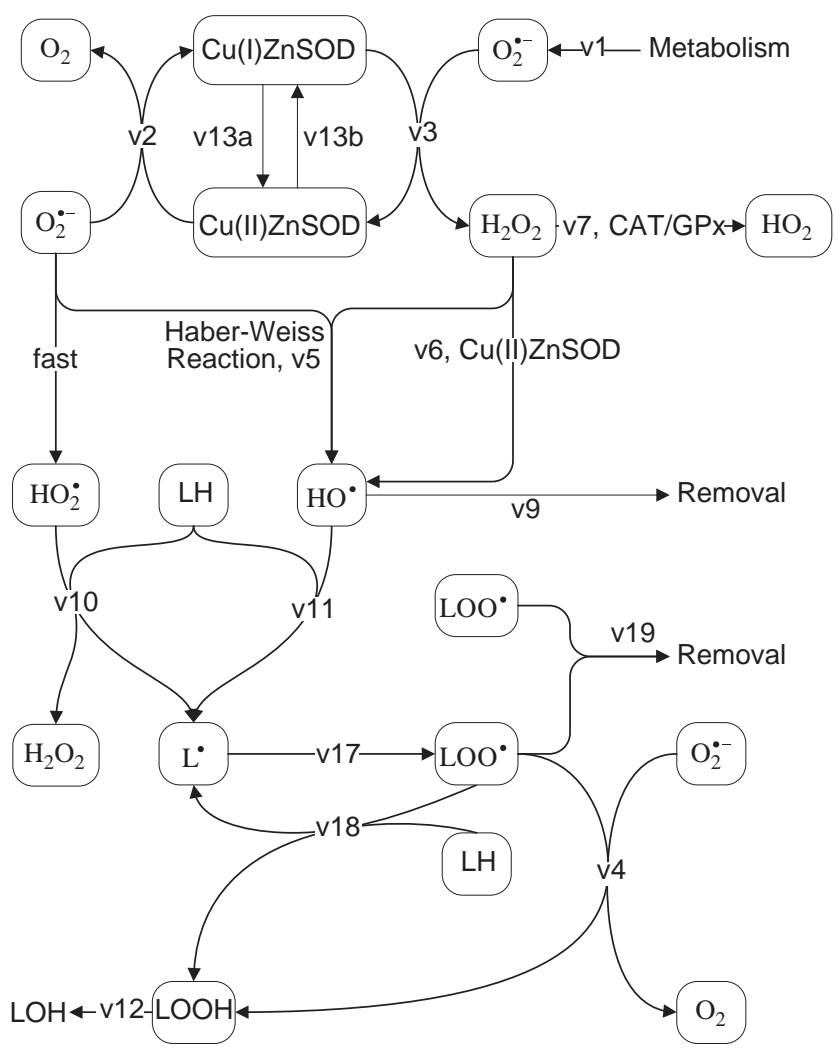

Fig. 1. Reactions included in the model to study three proposals for explaining the negative effects of high levels of superoxide dismutase (SOD). In brief, short circuiting of the SOD cycle is modelled by reactions $v_{2}, v_{3}, v_{13 a}$ and $v_{13 b}$, termination of lipid peroxidation by reactions $\mathrm{v}_{10}, \mathrm{v}_{11}, \mathrm{v}_{17}, \mathrm{v}_{18}, \mathrm{v}_{19}$ and $\mathrm{v}_{4}$ and peroxidation activity of CuZnSOD by reaction $v_{6}$. For details see text. 
indicated. While in these reactions the enzymes are unchanged, a special case exists for reactions $v_{2}$ and $v_{3}$. These reactions are enzyme catalysed, but the enzyme itself is modified during the reaction and therefore $\mathrm{CuZnSOD}$ is shown as substrate and product, respectively. It is assumed that $\mathrm{O}_{2}{ }^{-}$is produced by the cellular metabolism at a constant rate (reaction $\mathrm{v}_{1}$ ) and can then undergo several different reactions. (i) it can react with $\mathrm{Cu}$ (II)ZnSOD and produce $\mathrm{O}_{2}$ (the SOO part of the dismutation cycle), (ii) it can react with $\mathrm{Cu}(\mathrm{I}) \mathrm{ZnSOD}$ and generate $\mathrm{H}_{2} \mathrm{O}_{2}$ (the SOR part of the dismutation cycle), (iii) together with $\mathrm{H}_{2} \mathrm{O}_{2}$ it can give rise to $\mathrm{HO}^{\bullet}$ radicals via the iron catalysed Haber-Weiss reaction, (iv) it can react with lipid peroxyl radicals, $\mathrm{v}_{4}$, interrupting the lipid peroxidation cycle and (v) it stands in fast equilibrium with its conjugated base the perhydroxyl radical, $\mathrm{HO}_{2}^{\circ}$.

The possibility of short cutting the SOD cycle (proposal one) is realized by the reactions v13a and $\mathrm{v} 13 \mathrm{~b}$. If the corresponding rate constants have different values either SOO or SOR activity is favoured.

To test proposal two, reactions describing the lipid peroxidation cycle have to be implemented. Initiation of lipid peroxidation is caused by species that are reactive enough to abstract hydrogen atoms from lipid molecules. In the model $\mathrm{HO}^{\bullet}$ and $\mathrm{HO}_{2}^{\bullet}$ can start the chain reaction via reactions $\mathrm{v}_{10}$ and $\mathrm{v}_{11}$. Under aerobic conditions lipid carbon radicals $\left(\mathrm{L}^{\bullet}\right)$ react with oxygen to produce lipid peroxyl radical $\left(\mathrm{LOO}^{\bullet}\right)$ via reaction $\mathrm{v}_{17}$. Peroxyl radicals are capable of abstracting protons from other lipid molecules leading to a lipid hydroperoxide and another $\mathrm{L}^{\bullet}\left(\mathrm{v}_{18}\right)$. This represents the propagation stage of lipid peroxidation. This chain reaction can be interrupted in two ways. Either two $\mathrm{LOO}^{\bullet}$ molecules can react with each other $\left(\mathrm{v}_{19}\right)$ in a process of self-termination, or, as proposed, lipid peroxyl radicals can interact with superoxide, which now acts as chain breaker $\left(\mathrm{v}_{4}\right)$.

It is not completely clear, if the peroxidase activity associated with the reaction between $\mathrm{CuZnSOD}$ and hydrogen peroxide is caused by the release of hydroxyl radicals or carbonate radical anions (Yim et al., 1990; Goss et al., 1999). However, in our model the reaction is implemented as possible production of hydroxyl radicals from $\mathrm{H}_{2} \mathrm{O}_{2}\left(\mathrm{v}_{6}\right)$.

Finally, hydrogen peroxide is removed from the system by the enzymatic action of catalase or GPX. For simplicity this is represented as the action of a single enzyme $\left(v_{7}\right)$. Please note, that for clarity species whose concentrations are assumed to be constant (e.g. water, oxygen, protons, metal ions), are sometimes omitted from the diagram. The following list summarizes the reactions included in the model. As explained in the next section, the mass action law has been used for all reactions and the label $k_{x}$ denotes the rate constants used for the reactions. A list with a description and the numerical values used for the rate constants is given in Table 1.

(1) metabolism $\stackrel{k 1}{\longrightarrow} \mathrm{O}_{2}^{\bullet-}$

(2) $\mathrm{O}_{2}^{\cdot-}+\mathrm{Cu}(\mathrm{II}) \mathrm{ZnSOD} \stackrel{k_{2}}{\longrightarrow} \mathrm{O}_{2}+\mathrm{Cu}(\mathrm{I}) \mathrm{ZnSOD}$

(3) $\mathrm{O}_{2}^{\bullet-}+2 \mathrm{H}^{+}+\mathrm{Cu}(\mathrm{I}) \mathrm{ZnSOD} \stackrel{k 3}{\longrightarrow} \mathrm{H}_{2} \mathrm{O}_{2}+$ $\mathrm{Cu}(\mathrm{II}) \mathrm{ZnSOD}$

(4) $\mathrm{O}_{2}^{\bullet-}+\mathrm{LOO}^{\bullet}+\mathrm{H}^{+} \stackrel{k 4}{\longrightarrow} \mathrm{O}_{2}+\mathrm{LOOH}$

(5) $\mathrm{O}_{2}^{\bullet-}+\mathrm{H}_{2} \mathrm{O}_{2} \stackrel{k 5}{\longrightarrow} \mathrm{O}_{2}+2 \mathrm{HO}^{\bullet}+e^{-}$

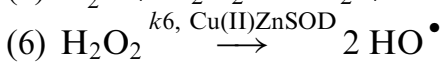

(7) $\mathrm{H}_{2} \mathrm{O}_{2} \stackrel{k 7, \mathrm{CAT} / \mathrm{GPX}}{\longrightarrow} \mathrm{H}_{2} \mathrm{O}+\frac{1}{2} \mathrm{O}_{2}$

(8) $\mathrm{HO}^{\bullet} \stackrel{k 9}{\longrightarrow}$ metabolism

(9) $\mathrm{HO}_{2}^{\bullet}+\mathrm{LH} \stackrel{k 10}{\longrightarrow} \mathrm{L}^{\bullet}+\mathrm{H}_{2} \mathrm{O}_{2}$

(10) $\mathrm{HO}^{\bullet}+\mathrm{LH} \stackrel{k 11}{\longrightarrow} \mathrm{L}^{\bullet}+\mathrm{H}_{2} \mathrm{O}$

(11) $\mathrm{LOOH} \stackrel{k 12}{\longrightarrow} \mathrm{LOH}+\frac{1}{2} \mathrm{O}_{2}$

(12) $\mathrm{Cu}(\mathrm{I}) \mathrm{ZnSOD} \stackrel{k 13 a}{\longrightarrow} \mathrm{Cu}(\mathrm{II}) \mathrm{ZnSOD}+e^{-}$

(13) $\mathrm{Cu}(\mathrm{II}) \mathrm{ZnSOD}+e^{-} \stackrel{k 13 b}{\longrightarrow} \mathrm{Cu}(\mathrm{I}) \mathrm{ZnSOD}$

(14) $\mathrm{L}^{\bullet}+\mathrm{O}_{2} \stackrel{k 17}{\longrightarrow} \mathrm{LOO}^{\bullet}$

(15) $\mathrm{LOO}^{\bullet}+\mathrm{LH}^{k 18} \longrightarrow \mathrm{L}^{\bullet}+\mathrm{LOOH}$

(16) $\mathrm{O}_{2}^{\bullet^{-}}+\mathrm{H}^{+} \stackrel{\text { fast }}{\leftrightarrow} \mathrm{HO}_{2}^{\bullet}$

(17) $\mathrm{LOO}^{\bullet}+\mathrm{LOO}^{\bullet} \stackrel{k 19}{\longrightarrow}$ removal

\subsection{The equations}

Based on the diagram shown in Fig. 1 and the list of reactions, the differential equations (ODE) of the model can be developed. The model consists of seven ODEs controlling the time course of $\operatorname{ROS}\left(\mathrm{O}_{2}^{\bullet}, \mathrm{H}_{2} \mathrm{O}_{2}, \mathrm{HO}^{\bullet}\right)$, lipid components $\left(\mathrm{L}^{\bullet}, \mathrm{LOO}^{\bullet}, \mathrm{LOOH}\right)$ and the oxidized form of SODs (Cu(II)ZnSOD). Two algebraic equations calculate the concentration of the reduced form of SOD $(\mathrm{Cu}(\mathrm{I}) \mathrm{ZnSOD})$ and of the perhydroxyl radical.

In all equations we use the simple mass action law since the molecular species under investigation in vivo do not exist in concentrations which would saturate the enzymes. SOD for instance is present in most tissues at concentrations around $10^{-5} \mathrm{M}$ (Tyler, 1975; Fridovich, 1978) compared to the $\mathrm{O}_{2}^{\bullet-}$ steady-state concentration of $10^{-11}-10^{-12} \mathrm{M}$ (Chance et al., 1979). Although the individual terms of the equations are normally straightforward, there are a few points worth mentioning. In two steps of the lipid peroxidation, substances are involved that do not appear in the equations (lipids (LH) and molecular oxygen). It is assumed that the concentration of these compounds is constant and can thus be included in the value of the rate constant. Furthermore, the superoxide radical is in fast equilibrium with its conjugated base, the perhydroxyl radical $\left(\mathrm{HO}_{2}^{\bullet} \rightleftarrows \mathrm{H}^{+}+\mathrm{O}_{2}^{\bullet}\right)$, with a p $K_{\mathrm{a}}$ of approximately 4.8. With a cellular $\mathrm{pH}$ of around 6.8 and the 
Table 1

Parameters and standard values used for the simulations

\begin{tabular}{|c|c|c|}
\hline Name & Value & Description \\
\hline$k_{1}$ & $6.6 \times 10^{-7} \mathrm{M} \mathrm{s}^{-1}$ & Rate of cellular superoxide generation. Calculated from Joenje et al. (1985). \\
\hline$k_{2}$ & $1.6 \times 10^{9} \mathrm{M}^{-1} \mathrm{~s}^{-1}$ & $\begin{array}{l}\text { Rate constant for the superoxide oxidase (SOO) step of the superoxide dismutase reaction. Assumed to be } \\
\text { identical to the overall dismutation rate that was taken from (Halliwell and Gutteridge, 1999). }\end{array}$ \\
\hline$k_{3}$ & $1.6 \times 10^{9} \mathrm{M}^{-1} \mathrm{~s}^{-1}$ & $\begin{array}{l}\text { Rate constant for the superoxide reductase (SOR) step of the superoxide dismutase reaction. Assumed to be } \\
\text { identical to the overall dismutation rate that was taken from (Halliwell and Gutteridge, 1999). }\end{array}$ \\
\hline$k_{4}$ & $10^{5} \mathrm{M}^{-1} \mathrm{~s}^{-1}$ & $\begin{array}{l}\text { Rate controlling the lipid peroxidation termination activity of } \mathrm{O}_{2}^{-}{ }^{-} \text {. Free parameter, since no value was } \\
\text { available in the literature. }\end{array}$ \\
\hline$k_{5}$ & $2 \times 10^{4} \mathrm{M}^{-1} \mathrm{~s}^{-1}$ & Iron catalysed Haber-Weiss reaction (Halliwell and Gutteridge, 1999). \\
\hline$k_{6}$ & $1 \mathrm{M}^{-1} \mathrm{~s}^{-1}$ & $\begin{array}{l}\text { Approximate upper limit calculated from the information given by Yim et al. (1990). Ca. } 1-10 \mu \mathrm{M} \mathrm{HO}{ }^{\bullet} \text { were } \\
\text { generated within } 6 \mathrm{~min} \text { in a solution containing } 1.25 \mu \mathrm{M} \text { SOD and } 30 \mathrm{mM} \mathrm{H}_{2} \mathrm{O}_{2} \text {. }\end{array}$ \\
\hline$k_{7}$ & $3.4 \times 10^{7} \mathrm{M}^{-1} \mathrm{~s}^{-1}$ & Rate constant for catalase. Taken from (Halliwell and Gutteridge, 1999). \\
\hline$k_{9}$ & $10^{6} \mathrm{~s}^{-1}$ & $\begin{array}{l}\text { Aggregated reaction rate of hydroxyl radicals with substrates outside the current model. A typical rate } \\
\text { constant of } 10^{9} \mathrm{M}^{-1} \mathrm{~s}^{-1} \text { and a substrate concentration of } 10^{-3} \mathrm{M} \text { was assumed (Halliwell and Gutteridge, } \\
\text { 1999). }\end{array}$ \\
\hline$k_{10}$ & $1000 \mathrm{~s}^{-1}$ & $\begin{array}{l}\text { Aggregated reaction rate of perhydroxyl radicals with lipids. Calculated from the rate constant of reaction } 3 \\
\text { Antunes et al. (1996) and under the assumption that the lipid concentration is constant at } 0.5 \mathrm{M} \text { (Antunes et } \\
\text { al., 1996). }\end{array}$ \\
\hline$k_{11}$ & $2.5 \times 10^{8} \mathrm{~s}^{-1}$ & $\begin{array}{l}\text { Aggregated reaction rate of hydroxyl radicals with lipids. Calculated from the rate constant of reaction } 1 \\
\text { Antunes et al. (1996) and under the assumption that the lipid concentration is constant at } 0.5 \mathrm{M} \text {. }\end{array}$ \\
\hline$k_{12}$ & $0.38 \mathrm{~s}^{-1}$ & $\begin{array}{l}\text { Removal of lipid hydroperoxides via phospholipid hydroperoxide GPX. The enzyme concentration is assumed } \\
\text { to be constant at } 3.8 \times 10^{-8} \mathrm{M} \text { (Antunes et al., 1996) and has been aggregated with the reaction constant from } \\
\text { reaction } 58 \text { Antunes et al. (1996). }\end{array}$ \\
\hline$k_{13 \mathrm{a}}$ & $0.0087 \mathrm{~s}^{-1}$ & $\begin{array}{l}\text { Aggregated reaction rate of } \mathrm{Cu}(\mathrm{I}) \mathrm{ZnSOD} \text { with a hypothetical electron acceptor different from superoxide. The } \\
\text { concentration of the electron acceptor was assumed to be } 1 \mu \mathrm{M} \text { and the rate constant was estimated to be } \\
\text { around } 8700 \mathrm{M}^{-1} \mathrm{~s}^{-1} \text { from Fig. 1A from Liochev and Fridovich (2000). }\end{array}$ \\
\hline$k_{13 \mathrm{~b}}$ & $0.0087 \mathrm{~s}^{-1}$ & $\begin{array}{l}\text { Aggregated reaction rate of } \mathrm{Cu}(\mathrm{II}) \mathrm{ZnSOD} \text { with a hypothetical electron donor different from superoxide. The } \\
\text { concentration of the electron donor was assumed to be } 1 \mu \mathrm{M} \text { and the rate constant was estimated to be around } \\
8700 \mathrm{M}^{-1} \mathrm{~s}^{-1} \text { from Fig. 1A from Liochev and Fridovich }(2000) \text {. }\end{array}$ \\
\hline$k_{17}$ & $3 \times 10^{4} \mathrm{~s}^{-1}$ & $\begin{array}{l}\text { Aggregated reaction rate of the autoxidation of lipid carbon radicals with molecular oxygen (present at a } \\
\text { constant concentration of } 10^{-4} \mathrm{M} \text { ). Data taken from Antunes et al. (1996). }\end{array}$ \\
\hline$k_{18}$ & $7 s^{-1}$ & $\begin{array}{l}\text { Aggregated reaction rate of the propagation stage of lipid peroxidation with lipids at a constant concentration } \\
\text { of } 0.5 \mathrm{M} \text {. Reaction } 9 \text { Antunes et al. (1996). }\end{array}$ \\
\hline$k_{19}$ & $8.8 \times 10^{4} \mathrm{M}^{-1} \mathrm{~s}^{-1}$ & Self-termination of lipid peroxyl radicals. Reaction 25 Antunes et al. (1996). \\
\hline $\mathrm{SOD}_{\text {total }}$ & $10^{-5} \mathrm{M}^{-1}$ & Total concentration of CuZnSOD (Tyler, 1975; Fridovich, 1978). \\
\hline cat & $10^{-5} \mathrm{M}^{-1}$ & Concentration of catalase. Assumed to be similar to $\mathrm{SOD}_{\text {total }}$ \\
\hline
\end{tabular}

Henderson-Hasselbalch equation $\left(\mathrm{pH}=\mathrm{p} K_{\mathrm{a}}+\log _{10}\right.$ (base/acid)), it follows that the $\mathrm{HO}_{2}^{\circ}$ concentration is ca. $1 \%$ of the superoxide concentration (Halliwell and Gutteridge, 1999; de Grey, 2002). This is expressed by Eq. (9). Another point is the conservation law regarding the amount of SOD. SOD can exist in a reduced or in an oxidized form, but the total amount is fixed in the model (no synthesis or degradation) and equal to $\mathrm{SOD}_{\text {total. }}$ Eq. (8) takes this into account by calculating the amount of $\mathrm{Cu}(\mathrm{I}) \mathrm{ZnSOD}$ from the relationship $\mathrm{Cu}(\mathrm{I}) \mathrm{ZnSOD}+\mathrm{Cu}(\mathrm{II}) \mathrm{ZnSOD}=\mathrm{SOD}_{\text {total }}$. Finally, the term $k_{9} \cdot \mathrm{HO}^{\bullet}$ in the equation for the hydroxyl radical needs some explanation. The model contains the main source of hydroxyl radicals in the cell while it only covers a single sink, namely the reactions with lipids via $\mathrm{v}_{11}$. To describe the fact that hydroxyl radicals are also removed from the system by reactions outside the scope of the model, the above term has been introduced. It represents the sum of all other sinks for $\mathrm{HO}^{\bullet}$.

$$
\begin{aligned}
\frac{\mathrm{dO}_{2}^{\bullet-}}{\mathrm{d} t}= & k_{1}-\left(k_{2} \cdot \mathrm{Cu}(\mathrm{II}) \mathrm{ZnSOD}+k_{3} \cdot \mathrm{Cu}(\mathrm{I}) \mathrm{ZnSOD}\right. \\
& \left.+k_{4} \cdot \mathrm{LOO}^{\bullet}+k_{5} \cdot \mathrm{H}_{2} \mathrm{O}_{2}\right) \mathrm{O}_{2}^{\bullet}-k_{10} \cdot \mathrm{HO}_{2}^{\bullet}
\end{aligned}
$$

$$
\begin{aligned}
\frac{\mathrm{dH}_{2} \mathrm{O}_{2}}{\mathrm{~d} t}= & k_{3} \mathrm{O}_{2}^{\bullet-} \cdot \mathrm{Cu}(\mathrm{I}) \mathrm{ZnSOD}+k_{10} \cdot \mathrm{HO}_{2}^{\bullet} \\
& -\left(k_{5} \mathrm{O}_{2}^{\bullet-}+k_{6} \cdot \mathrm{Cu}(\mathrm{II}) \mathrm{ZnSOD}\right. \\
& \left.+k_{7} \cdot \text { cat }\right) \cdot \mathrm{H}_{2} \mathrm{O}_{2}
\end{aligned}
$$

$$
\begin{aligned}
\frac{\mathrm{dHO}^{\bullet}}{\mathrm{d} t}= & k_{5} O_{2}^{\bullet-} \cdot \mathrm{H}_{2} \mathrm{O}_{2} \\
& +2 k_{6} \mathrm{H}_{2} \mathrm{O}_{2} \cdot \mathrm{Cu}(\mathrm{II}) \mathrm{ZnSOD} \\
& -\left(k_{9}+k_{11}\right) \cdot \mathrm{HO}^{\bullet}
\end{aligned}
$$

$$
\frac{\mathrm{d} L^{\bullet}}{\mathrm{d} t}=k_{10} \cdot \mathrm{HO}_{2}^{\bullet}+k_{11} \cdot \mathrm{HO}^{\bullet}+k_{18} \cdot \mathrm{LOO}^{\bullet}-k_{17} \cdot \mathrm{L}^{\bullet}
$$




$$
\begin{aligned}
\frac{\mathrm{dLOO}^{\bullet}}{\mathrm{d} t}= & k_{17} \cdot \mathrm{L}^{\bullet}-k_{18} \cdot \mathrm{LOO}^{\bullet}-k_{4} \mathrm{O}_{2}^{\bullet-} \cdot \mathrm{LOO}^{\bullet} \\
& -2 k_{19} \cdot \mathrm{LOO}^{\bullet} \cdot \mathrm{LOO}^{\bullet}
\end{aligned}
$$

$\frac{\mathrm{dLOOH}}{\mathrm{d} t}=k_{18} \cdot \mathrm{LOO}^{\bullet}-k_{12} \cdot \mathrm{LOOH}+k_{4} \mathrm{O}_{2}^{\bullet-} \cdot \mathrm{LOO}^{\bullet}$

$$
\begin{aligned}
\frac{\mathrm{dCu}(\mathrm{II}) \mathrm{ZnSOD}}{\mathrm{d} t}= & \left(k_{3} \mathrm{O}_{2}^{\cdot-}+k_{13 a}\right) \cdot \mathrm{Cu}(\mathrm{I}) \mathrm{ZnSOD} \\
& -\left(k_{2} \mathrm{O}_{2}^{--}+k_{13 b}\right) \cdot \mathrm{Cu}(\mathrm{II}) \mathrm{ZnSOD}
\end{aligned}
$$

$\mathrm{Cu}(\mathrm{I}) \mathrm{ZnSOD}=\mathrm{SOD}_{\text {total }}-\mathrm{Cu}(\mathrm{II}) \mathrm{ZnSOD}$

$\mathrm{HO}_{2}^{\bullet}=\mathrm{O}_{2}^{\bullet-} / 100$

\section{Results}

\subsection{Standard simulation}

The set of differential equations was solved numerically with Mathematica ${ }^{T M}$. Fig. 2 shows the results of the standard simulation, an integration over time, using the parameter values presented in Table 1. After $1000 \mathrm{~s}$ all variables have practically reached their steady-state concentrations. The kinetics of some variables $\left(\mathrm{HO}^{\bullet}\right.$, $\mathrm{H}_{2} \mathrm{O}_{2}, \mathrm{O}_{2}^{-}$) is very fast (reaching equilibrium within a few $\mathrm{ms}$ ), while it is much slower for others $\left(\mathrm{L}^{\bullet}, \mathrm{LOO}^{\bullet}\right.$, $\mathrm{LOOH})$. Since the absolute concentrations of the different species vary by several orders of magnitude, different variables are shown on different scales as indicated by the various axes.

\subsection{Short circuiting the SOD cycle}

It has been proposed that cellular electron donors can short circuit the SOD dismutation cycle. Parameters $k_{13 a}$ and $k_{13 \mathrm{~b}}$ were changed to study this idea. Under standard conditions $k_{13 \mathrm{a}} / k_{13 \mathrm{~b}}=1$ so that neither SOO nor SOR activities are favoured. To favour the SOR half-cycle the ratio $k_{13 \mathrm{a}} / k_{13 \mathrm{~b}}$ was reduced to $1 / 10$ and the steady-state values of the variables were calculated for $\mathrm{SOD}_{\text {total }}$ concentrations from $10^{-6}$ to $10^{-5} \mathrm{M}$ (Fig. 3a). To be sure that the observed effects stem from the manipulation of the dismutation reaction, the lipid peroxidation part was disabled by setting $k_{10}=k_{11}=0$. As expected the superoxide radical steady-state concentration drops with increasing amounts of total SOD while the hydroxyl radical concentration has a minimum for intermediate SOD levels. For low concentrations of SOD (and thus high superoxide levels), $\mathrm{HO}^{\bullet}$ increases because of the Haber-Weiss reaction and for high levels of SOD the

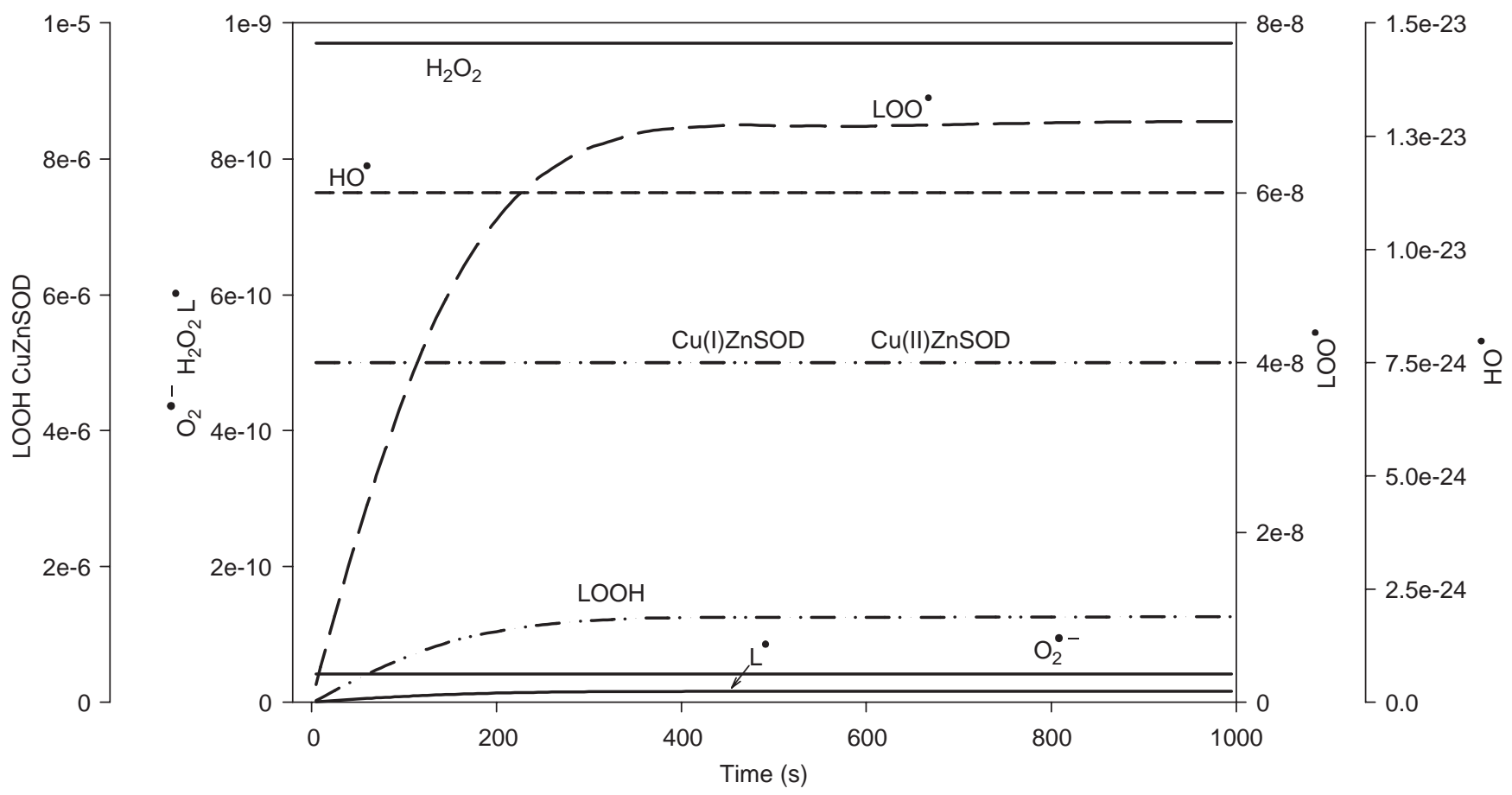

Fig. 2. Time course of the model variables if the simulation is performed with the default parameter values of Table 1 . After $1000 \mathrm{~s}$ all variables have reached their steady-state concentrations. Because the absolute concentrations of the different variables vary by several orders of magnitude, different scales and axes are used. LOOH and both forms of CuZnSOD are shown on the far left axis, the superoxide radical, hydrogen peroxide and lipid carbon radicals are shown on the left axis, the right axis is for $\mathrm{LOO}^{\bullet}$ and the far right axis shows the concentration of the hydroxyl radical. A similar arrangement is also used for the other diagrams. 

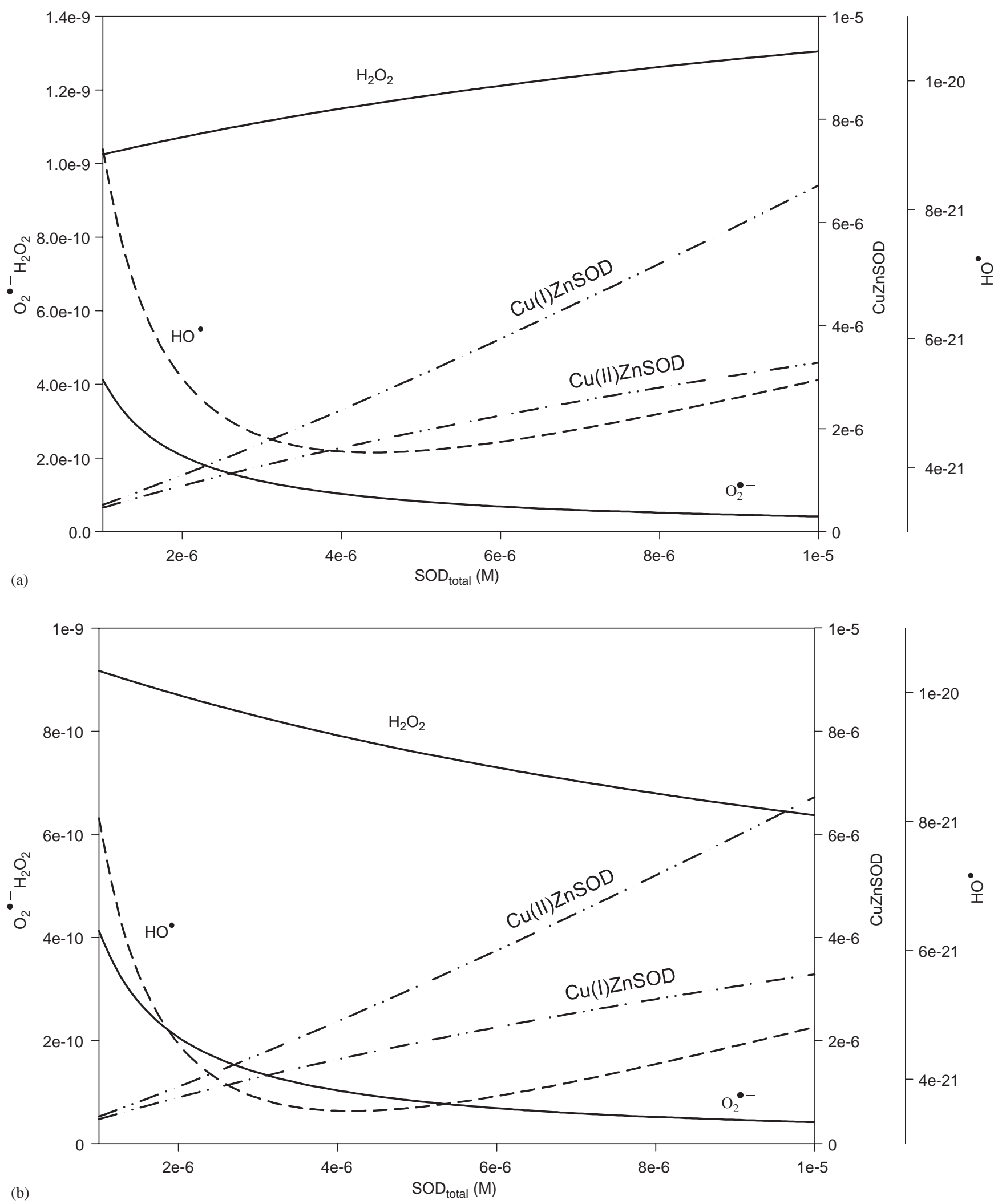

Fig. 3. Effects of short-circuiting the SOD cycle in favour of superoxide reductase (a) or superoxide oxidase (b) activity. To boost SOR activity $k_{13 \mathrm{~b}}$ was set to 10 times $k_{13 \mathrm{a}}$ and to disable distracting lipid peroxidation reactions $k_{10}$ and $k_{11}$ were set to zero. Under those conditions steady-state values of the shown variables were calculated for $\mathrm{SOD}_{\text {total }}$ ranging from $10^{-5}$ to $10^{-7} \mathrm{M}$. To study the effects of increased SOO activity (b) the same procedure was followed but $k_{13 \mathrm{a}}$ was set to 10 times $k_{13 \mathrm{~b}}$. 
level of hydroxyl radicals rises because of the SOD peroxidase activity. From Eq. (7) it follows that under steady-state conditions the ratio of reduced to oxidized SOD is given by: $\mathrm{Cu}(\mathrm{I}) \mathrm{ZnSOD} / \mathrm{Cu}(\mathrm{II}) \mathrm{ZnSOD}=$ $\left(k_{13 \mathrm{~b}}+k_{2} \cdot \mathrm{O}_{2}^{\bullet-}\right) /\left(k_{13 \mathrm{a}}+k_{3} \cdot \mathrm{O}_{2}^{\bullet-}\right)$. If total SOD concentration is low and superoxide levels are therefore high the ratio is close to unity (for $k_{2}=k_{3}$ ). However, if $\mathrm{SOD}_{\text {total }}$ increases and superoxide levels fall, the ratio climbs to $k_{13 \mathrm{~b}} / k_{13 \mathrm{a}}$. Consequently this means, that large amounts of $\mathrm{SOD}_{\text {total }}$ favour SOR activity, since more reduced than oxidized SOD is available for the reaction with superoxide radicals. Therefore, the $\mathrm{H}_{2} \mathrm{O}_{2}$ equilibrium concentration is indeed increasing with the total amount of SOD.

Instead of boosting SOR activity the cell might be in a metabolic state where $k_{13 \mathrm{a}} / k_{13 \mathrm{~b}}>1$. While for low SOD concentrations the $\mathrm{Cu}(\mathrm{I}) \mathrm{ZnSOD} / \mathrm{Cu}(\mathrm{II}) \mathrm{ZnSOD}$ ratio is still close to one, it decreases to $k_{13 \mathrm{~b}} / k_{13 \mathrm{a}}$ for high values of SOD. In this case the oxidized form of SOD increases over the reduced form (see Fig. 3b) and consequently the SOO activity if favoured. This leads to a declining $\mathrm{H}_{2} \mathrm{O}_{2}$ concentration with increasing $\mathrm{SOD}_{\text {total }}$.

\subsection{Termination of lipid peroxidation}

The toxicity of high doses of SOD led Nelson et al. (1994) to suggest that superoxide radicals can both initiate and terminate lipid peroxidation. They proposed that $\mathrm{O}_{2}^{-}$- can react with lipid peroxyl radicals interrupting the peroxidation chain reaction. The rate of this reaction is in our model controlled by the rate constant $k_{4}$. For this reaction no value could be found in the literature and therefore a medium-sized value of $10^{5} \mathrm{M}^{-1} \mathrm{~s}^{-1}$ was used for the standard simulation.

The larger $k_{4}$, the more beneficial should be superoxide for the cell. $k_{4}$ was therefore set to a very large value $\left(10^{10}\right)$ and the total SOD concentration was varied from $10^{-5}$ to $10^{-7} \mathrm{M}$ (Fig. 4). However, even with such a large rate constant, high levels of SOD (low levels of superoxide) do not lead to increased steady-state concentrations of $\mathrm{L}^{\bullet}, \mathrm{LOO}^{\bullet}$ or $\mathrm{LOOH}$. Lipid peroxyl radicals seem completely independent of SOD, while $\mathrm{L}^{\bullet}$ and $\mathrm{LOOH}$ are independent at high levels of SOD and actually increase for low levels. Another important observation is that hydrogen peroxide is actually rising with the amount of SOD.

To understand these simulation results we construct a simpler model that is biochemically less realistic, but can be solved analytically (Fig. 5). In this simplified model superoxide is either removed by SOD, initiates lipid peroxidation $\left(k_{2}\right)$, or terminates it by reaction with $\mathrm{LOO}^{\bullet}\left(\mathrm{v}_{4}\right)$. This system can be described by the following reactions (constants $k_{x}$ correspond to the constants of the full model, while constants $c_{x}$ represent

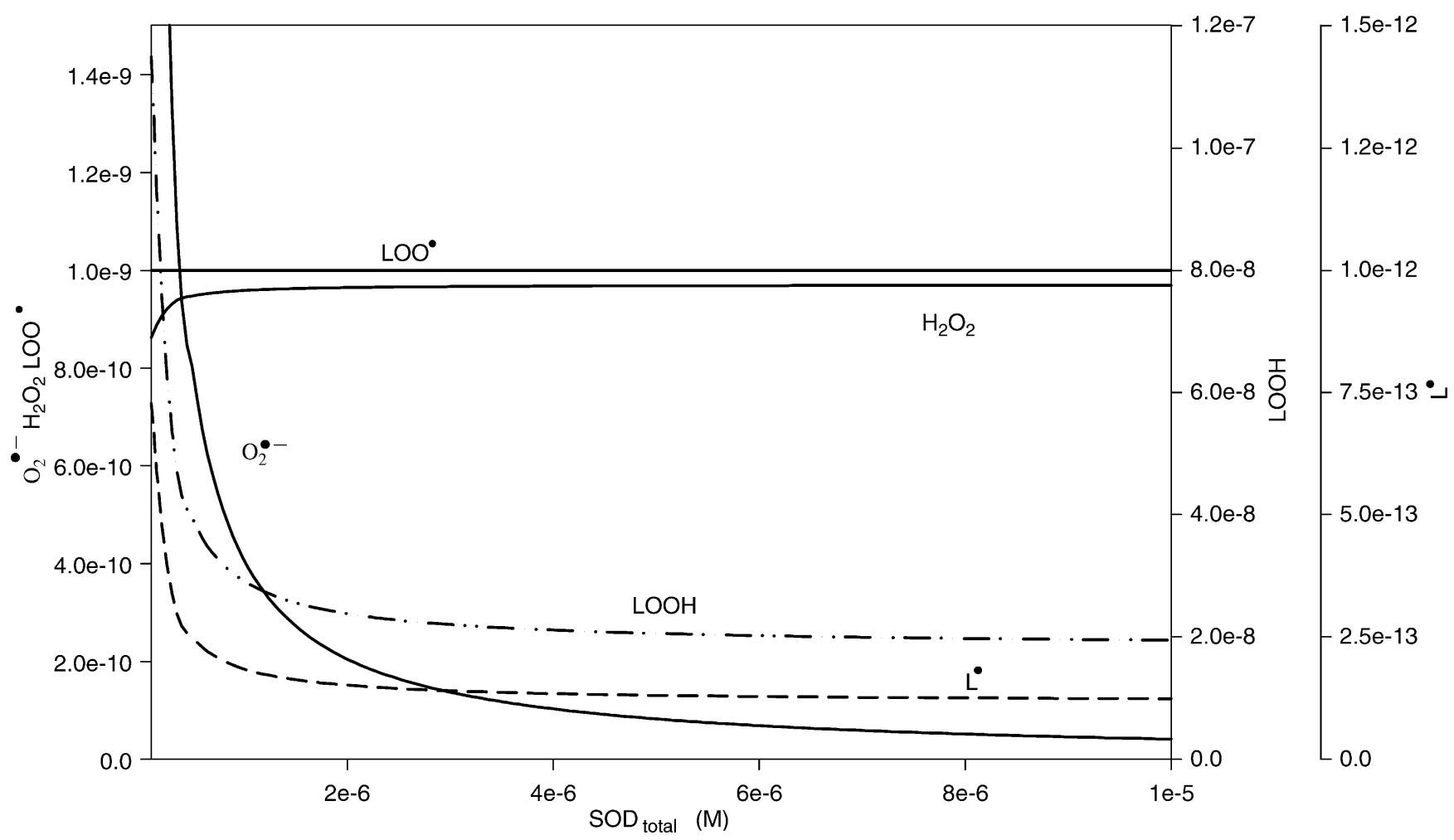

Fig. 4. Influence of SOD on the termination of lipid peroxidation. To increase the relevance of the termination reaction a very large value was used for the rate constant $k_{4}\left(10^{10} \mathrm{M}^{-1} \mathrm{~s}^{-1}\right)$ and then the steady-state values of the shown variables were calculated for $\mathrm{SOD}_{\text {total }}$ ranging from $10^{-5}$ to $10^{-7} \mathrm{M}$. To simplify the interpretation of the results the generation of hydroxyl radicals was disabled for these simulations by setting $k_{5}=k_{6}=0$. 


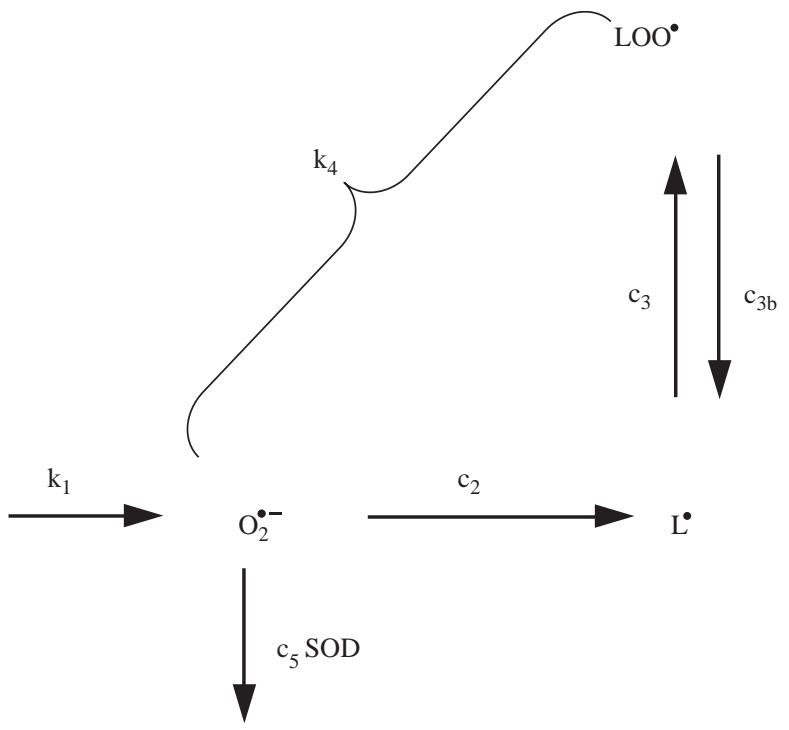

$$
\begin{aligned}
\mathrm{O}_{2, \mathrm{ss}}^{\bullet-}=\frac{\mathrm{k}_{1}}{2 \mathrm{c}_{2}+\mathrm{c}_{5} \cdot \mathrm{SOD}} \\
\mathrm{LOO}_{\mathrm{ss}}^{\bullet}=\frac{\mathrm{c}_{2}}{\mathrm{k}_{4}} \\
\mathrm{~L}_{\mathrm{ss}}^{\bullet}=\frac{\mathrm{c}_{2} \cdot \mathrm{c}_{3 \mathrm{~b}}}{\mathrm{c}_{3} \cdot \mathrm{k}_{4}}+\frac{\mathrm{k}_{1} \cdot \mathrm{c}_{2}}{\mathrm{k}_{3} \cdot\left(2 \mathrm{c}_{2}+\mathrm{c}_{5} \cdot \mathrm{SOD}\right)}
\end{aligned}
$$

Fig. 5. Simplified model used to understand the behaviour of the model simulation shown in Fig. 4. This system can be described with three simple ODEs (see text for details) that can be analysed analytically. The right part of the diagram shows the dependencies of the steady-state concentrations of the radical species on the parameters. Interestingly, the lipid peroxyl radical level does not depend on the amount of SOD.

new constants of this simplified model):

$$
\begin{aligned}
& \frac{\mathrm{dO}_{2}^{\bullet-}}{\mathrm{d} t}=k_{1}-\left(k_{4} \cdot \mathrm{LOO}^{\bullet}+c_{2}+c_{5} \cdot \mathrm{SOD}\right) \cdot \mathrm{O}_{2}^{\bullet-} \\
& \frac{\mathrm{d} L^{\bullet}}{\mathrm{d} t}=c_{2} \cdot \mathrm{O}_{2}^{\bullet-}-c_{3} \cdot \mathrm{L}^{\bullet} \\
& \frac{\mathrm{dLOO}^{\bullet}}{\mathrm{d} t}=c_{3} \cdot \mathrm{L}^{\bullet}-k_{4} \cdot \mathrm{LOO}^{\bullet} \cdot \mathrm{O}_{2}^{\bullet-} \\
& \quad \Rightarrow \\
& O_{2, \mathrm{ss}}^{\bullet}=\frac{k_{1}}{2 c_{2}+c_{5} \cdot \mathrm{SOD}} \\
& \mathrm{LOO}_{\mathrm{ss}}^{\bullet}=\frac{c_{2}}{k_{4}} \\
& L_{\mathrm{ss}}^{\bullet}=\frac{c_{2} \cdot c_{3 \mathrm{~b}}}{c_{3} \cdot k_{4}}+\frac{k_{1} \cdot c_{2}}{k_{3} \cdot\left(2 c_{2}+c_{5} \cdot \mathrm{SOD}\right)}
\end{aligned}
$$

The steady-state solutions confirm that lipid peroxyl radicals only depend on the ratio of the rates of lipid peroxidation initiation and termination, but not on SOD. $\mathrm{L}^{\bullet}$ levels do depend on SOD, but only for low concentrations. Otherwise, the second term tends to zero and the $\mathrm{L}^{\bullet}$ concentration is constant and equal to the first term. The simple model predicts that the back reaction of lipid peroxidation $\left(c_{3 \mathrm{~b}}\right)$ is responsible for the plateau of $\mathrm{L}^{\bullet}$ radicals at high amounts of SOD. Disabling the corresponding reaction in the full model $\left(k_{18}\right)$ does indeed cause the lipid carbon radical concentration drop to zero for high SOD levels, verifying the results of the simplified model (data not shown).

The important insight from this analysis is that the equilibrium concentration of $\mathrm{LOO}^{\bullet}$ radicals does depend on the rate constant of the proposed termination reaction with superoxide $\left(k_{4}\right)$, but not on the superoxide concentration itself. The reason is that a change in the $\mathrm{O}_{2}^{\bullet}$ - level affects the initiation of lipid peroxidation to the same degree as the termination. However, these arguments do not explain the rise of hydrogen peroxide. This important phenomenon will be clarified in the section Alternative Pathway Mechanism.

\subsection{SOD as radical generator}

We also studied the effects of the peroxidase function of CuZnSOD. For this purpose we varied the rate constant of this reaction $\left(k_{6}\right)$ from its standard value, $1 \mathrm{M}^{-1} \mathrm{~s}^{-1}$, to $10 \mathrm{M}^{-1} \mathrm{~s}^{-1}$ and observed the effects on the steady-state values of the variables. It turns out that the hydroxyl radical level does vary substantially (ca. 9fold), but the equilibrium concentrations of all other variables changes by less than $0.01 \%$ (data not shown). The reason and possible implications of this behaviour are elaborated on in the discussion.

\subsection{Alternative pathway mechanism}

The simulation shown in Fig. 4 was performed to study the effects of varying SOD concentrations on the reactions involved in lipid peroxidation. A quite unexpected result was the change of the hydrogen peroxide concentration, which was not further explained in the section Termination of lipid peroxidation. For the simulation shown in Fig. $4, k_{13 \mathrm{a}}$ was equal to $k_{13 \mathrm{~b}}$ so that neither SOO nor SOR activity was favoured and consequently the amount of SOD should have no influence on the $\mathrm{H}_{2} \mathrm{O}_{2}$ concentration. Closer inspection of this phenomenon revealed that the variation of hydrogen peroxide disappeared when perhydroxyl radical 


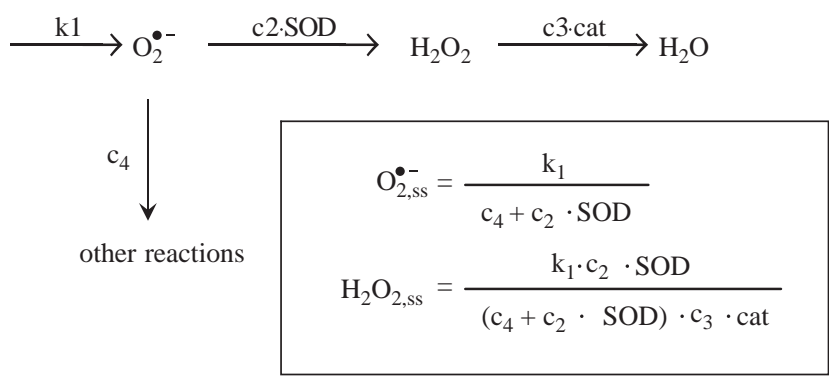

Fig. 6. Simplified model used to understand the Alternative Pathway mechanism. This system can be described by two ordinary differential equations (see text for details) that can be solved analytically for the steady-state conditions. The expression for $\mathrm{H}_{2} \mathrm{O}_{2, \mathrm{ss}}$ simplifies to $k_{1} /\left(c_{3} *\right.$ cat $)$ if there are no other reactions $\left(c_{4}=0\right)$, making the hydrogen peroxide concentration independent of SOD.

driven membrane damage was disabled $\left(k_{10}=0\right)$ (data not shown). To understand this behaviour we use again a simplified version of the full model (Fig. 6). The complete lipid peroxidation part has been omitted and also the rest has been simplified as much as possible. In contrast to the simple reactions discussed in the introduction, the model contains an additional alternative pathway for superoxide radicals (via $c_{4}$ ).

$$
\begin{aligned}
& \frac{\mathrm{dO}_{2}^{\bullet-}}{\mathrm{d} t}=k_{1}-c_{4} \cdot \mathrm{O}_{2}^{\bullet-}-c_{2} \cdot \mathrm{SOD} \cdot \mathrm{O}_{2}^{\bullet-} \\
& \frac{\mathrm{dH} \mathrm{O}_{2}}{\mathrm{~d} t}=c_{2} \cdot \mathrm{SOD} \cdot \mathrm{O}_{2}^{\bullet-}-c_{3} \cdot \mathrm{cat} \cdot \mathrm{H}_{2} \mathrm{O}_{2} \\
& \Rightarrow \\
& O_{2, \mathrm{ss}}^{\bullet}=\frac{k_{1}}{c_{4}+c_{2} \cdot \mathrm{SOD}} \\
& \mathrm{H}_{2} \mathrm{O}_{2, \mathrm{ss}}=\frac{k_{1} \cdot c_{2} \cdot \mathrm{SOD}}{\left(c_{4}+c_{2} \cdot \mathrm{SOD}\right) \cdot c_{3} \cdot \mathrm{cat}}
\end{aligned}
$$

Without alternative pathway $\left(c_{4}=0\right)$ SOD cancels out of the expression for the $\mathrm{H}_{2} \mathrm{O}_{2}$ equilibrium concentration. With alternative pathway; however, the dependency remains and rising levels of SOD lead to increased steady-state concentrations of hydrogen peroxide.

\section{Discussion}

SOD and catalase are two of the major enzymes of the cellular antioxidant system. It has therefore often been proposed that the negative effects seen with high levels of SOD are caused by an increased level of the product of the dismutation reaction, hydrogen peroxide. However, for a simple reaction system consisting only of SOD and catalase or GPX this cannot be an explanation, since under steady-state conditions SOD removes superoxide radicals exactly at the rate of its production. To nevertheless account for the observed increased oxidative stress associated with elevated levels of SOD, we studied in this work a larger reaction network and investigated three ideas from the literature by developing and simulating a mathematical model of the involved biochemical reactions. This resulted in a system of seven differential and two algebraic equations that were solved numerically using Mathematica.

Technically, only one of the three proposals (SOD cycle short circuiting, termination of lipid peroxidation, SOD as radical generator) worked. If an intracellular electron donor exists that short cuts the oxidation/ reduction cycle of $\mathrm{CuZnSOD}$ by reducing the copper atom at the active site of $\mathrm{CuZnSOD}$ from $\mathrm{Cu}$ (II) to $\mathrm{Cu}(\mathrm{I})$ the enzyme acts predominantly as SOR. Under these conditions an increase in the total SOD concentration leads, as proposed (Liochev and Fridovich, 2000), to an increase of the hydrogen peroxide steadystate levels (Fig. 3a). But there are two points that limit the generality of this mechanism. In their experiments Liochev and Fridovich demonstrated that $\mathrm{K}_{4} \mathrm{Fe}(\mathrm{CN})_{6}$ can indeed react as electron donor or acceptor with CuZnSOD. However, they could not show this behaviour with the manganese containing SOD, although increased oxidative stress is also associated with over expression of MnSOD (Bloch and Ausubel, 1986; Omar and McCord, 1990; Zhong et al., 1996). While it can be argued that a suitable redox partner for MnSOD simply has not yet been identified, the more serious problem is that the effect can also work in reverse. If in the cell a substance acts predominantly to oxidize CuZnSOD, and thus enhance its SOO activity, increasing the amount of total SOD actually leads to a reduction of the $\mathrm{H}_{2} \mathrm{O}_{2}$ level (Fig. 3b). In most experiments performed so far SOD overexpression led to increased oxidative stress, but a priori there is no reason why cells should always be in a state that enhances SOR and not SOO activity. This weakens the generality of the idea.

Termination of lipid peroxidation by superoxide radicals was proposed as beneficial reaction of $\mathrm{O}_{2}^{\bullet-}$ to explain the negative effects of over-scavenging the radical (Nelson et al., 1994). According to this idea too much SOD would lead to an increased lipid peroxidation chain length and thus to increased oxidative stress. Surprisingly, the simulations show that this idea does not work in our model. The steady-state concentration of lipid radicals and lipid hydroperoxides decreases monotonically with the amount of SOD while lipid peroxyl radicals do not depend at all on SOD (Fig. 4). This behaviour finally stems from the fact that superoxide radicals terminate and initiate lipid damage so that changes in the radical concentration affect both processes equally. An important message that can be learned from these simulations is that already a small network with few feed backs and non-linearities can display such a complex behaviour that intuition has difficulties to predict the outcome. This demonstrates 
how important it is to support verbal ideas by computational simulations.

The third mechanism we explored is the function of $\mathrm{CuZnSOD}$ as free radical generator. Simulations showed that the equilibrium concentration of $\mathrm{HO}^{\bullet}$ radicals increases roughly in proportion to rate constant $k_{6}$, but that the levels of the other variables changed by less then $0.01 \%$. The reason is that the hydroxyl radical steady-state concentration is many orders of magnitude below the concentrations of the other molecular species. And although it is extremely reactive, it seems that the main damage to lipids is not caused by the hydroxyl radical, but by the perhydroxyl radical that exists in much higher concentrations. This result is also in agreement with detailed simulations by Antunes et al. (1996).

In addition to the simulation results there are also other arguments that make it unlikely that hydroxyl radicals generated by $\mathrm{CuZnSOD}$ or changes of the lipid peroxidation are responsible for the negative consequences of high levels of SOD. In contrast to the other types of SODs MnSOD is resistant to inactivation by $\mathrm{H}_{2} \mathrm{O}_{2}$ and does not catalyse the formation of hydroxyl radicals (Yim et al., 1990). But at least three reports demonstrated that also overexpression of MnSOD leads to sensitization to oxidative damage (Bloch and Ausubel, 1986; Omar and McCord, 1990; Zhong et al., 1996), which means that in these cases an increased hydroxyl radical production by SOD cannot be responsible for the observed effects. Furthermore, Scott et al. (1987) generated Escherichia coli with 10 times increased FeSOD levels and measured directly the amount of hydrogen peroxide produced under oxidative stress. The quantity of $\mathrm{H}_{2} \mathrm{O}_{2}$ generated after $30 \mathrm{~min}$ of $2 \mathrm{mM}$ paraquat treatment was $70 \%$ higher in case of the SOD overproducer. So we are looking for a mechanism that influences the hydrogen peroxide level and is not restricted to lipid damage.

In addition to short circuiting the SOD cycle we discovered a further mechanism that influences $\mathrm{H}_{2} \mathrm{O}_{2}$ levels (Fig. 4), which we termed Alternative Pathway mechanism. A mathematical analysis showed that as soon as superoxide radicals have alternative reaction pathways (in addition to the reaction with SOD) increased amounts of SOD do indeed cause increased steady-state levels of $\mathrm{H}_{2} \mathrm{O}_{2}$. Although it still holds that under steady-state conditions superoxide is generated at the same rate with which it is removed, we have now the option to influence the relative flux through the different pathways. Increasing $\mathrm{SOD}$ redirects $\mathrm{O}_{2}^{\bullet}-$ away from the alternative pathways towards the reaction with SOD. This result is quite similar to the conclusions obtained by Gardner et al. (2002) who studied a minimalist mathematical model of superoxide generation and consumption. However, their model did not include hydrogen peroxide consuming steps so that they could

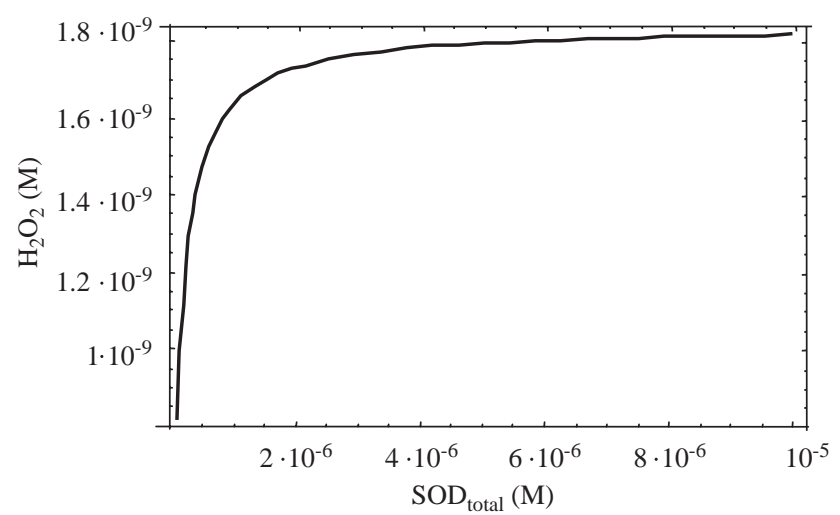

Fig. 7. Effect of the Alternative Pathway mechanism on the dependence of hydrogen peroxide on the SOD concentration. This curve was calculated according to the equation shown in Fig. 6. The magnitude of the effect depends strongly on the value of $c_{4}$ and for this simulation a $c_{4}$ of 20,000, ten times the value used for the other simulations, has been used. Why such a high value might nevertheless be physiological is discussed in the text.

only study production rates and not steady-state levels. They were also not concerned with the evaluation of mechanisms proposed in the literature. The two studies therefore complement and support each other by using different approaches. Another idea along these lines is the work of Buettner et al. (2000). They concentrated on manganese SOD and included variable superoxide production rates in their model. They showed that under certain conditions superoxide removal does actually pull more superoxide into the system, leading to an increase in the flux of $\mathrm{H}_{2} \mathrm{O}_{2}$ that is directly proportional to the amount of MnSOD.

In the simulation shown in Fig. 4 the hydrogen peroxide concentration did not change much, but in the model only two alternative pathways exist (initiation and termination of lipid peroxidation). In vivo all reactions of superoxide, apart from the reaction with SOD are alternative pathways and thus the flux through these pathways will be much larger than in this model. From the equation for the $\mathrm{H}_{2} \mathrm{O}_{2}$ steady-state concentration shown in Fig. 6 it can be seen that the hydrogen peroxide level depends linearly on SOD if $c_{4}$ tends to infinity. Fig. 7 shows a plot of these equations with a $k_{10}$ value 10 times larger than the standard value used for the simulations. The variation in SOD now leads to a two-fold change in the $\mathrm{H}_{2} \mathrm{O}_{2}$ equilibrium level.

The alternative pathway mechanism is a very general explanation for SOD associated oxidative stress since it does not depend on a special cell state (SOR activity favoured over SOO activity) nor on specific properties of SOD enzymes (peroxidase activity of CuZnSOD, but not MnSOD). We therefore think that it might be the common mechanism for the detrimental effects seen in cells and organisms with increased levels of the different forms of SOD. 


\section{References}

Amstad, P., Peskin, A., Shah, G., Mirault, M.-E., Moret, R., Zbinden, I., Cerutti, P., 1991. The balance between $\mathrm{Cu}, \mathrm{Zn}$-superoxide dismutase and catalase affects the sensitivity of mouse epidermal cells to oxidative stress. Biochemistry 30, 9305-9313.

Amstad, P., Moret, R., Cerutti, P., 1994. Glutathione peroxidase compensates for the hypersensitivity of $\mathrm{Cu}, \mathrm{Zn}$-superoxide dismutase overproducers to oxidant stress. J. of Biological Chemistry 269, 1606-1609.

Antunes, F., Salvador, A., Marinho, H.S., Alves, R., Pinto, R.E., 1996. Lipid peroxidation in mitochondrial inner membranes. I. An integrative kinetic model. Free Radical Biology \& Medicine 21, 917-943.

Avraham, K.B., Schickler, M., Sapoznikov, D., Yarom, R., Groner, Y., 1988. Down's syndrome: Abnormal neuromuscular junction in tongue of transgenic mice with elevated levels of human $\mathrm{Cu} / \mathrm{Zn}$ superoxide dismutase. Cell 54, 823-929.

Bannister, J.V., Bannister, W.H., Rotilio, G., 1987. Aspects of the structure, function, and applications of superoxide dismutase. CRC Crit. Rev. Biochem. 22, 111-180.

Bloch, C.A., Ausubel, F.M., 1986. Paraquat mediated selection for mutations in the manganese superoxide dismutase gene sodA. J. Bacteriol. 168, 795-798.

Brooksbank, B.W.L., Balazs, R., 1984. Superoxide dismutase, glutathione peroxidase and lipoperoxidation in Down's syndrome fetal brain. Dev. Brain Res. 16, 37.

Buettner, G.R., Ng, C., Oberley, L.W., Rodgers, V.G., Schafer, F.Q., 2000. Does MnSOD influence $\mathrm{H}_{2} \mathrm{O}_{2}$ production in mitochondria? Free Rad. Biol. Med. 29, S21.

Ceballos-Picot, I., Nicole, A., Briand, P., Grimber, G., Delacourte, A., Defossez, A., Javoy-Agid, F., Lafon, M., Blouin, J.L., Sinet, P.M., 1991. Neuronal-specific expression of human copper-zinc superoxide dismutase gene in transgenic mice: Animal model of gene dosage effects in Down's syndrome. Brain Res. 552, 198-214.

Ceballos-Picot, I., Nicole, A., Clément, M., Bourre, J.-M., Sinet, P.-M., 1992. Age-related changes in antioxidant enzymes and lipid peroxidation in brains of control and transgenic mice overexpressing copper-zinc superoxide dismutase. Mutat. Res. 275, 281-293.

Chan, P.H., Kawase, M., Murakami, K., Chen, S.F., Li, Y., Calagui, B., Reola, L., Carlson, E., Epstein, C.J., 1998. Overexpression of SOD1 in transgenic rats protects vulnerable neurons against ischemic damage after global cerebral ischemia and reperfusion. J. Neurosci. 18, 8292-8299.

Chance, B., Sies, H., Boveris, A., 1979. Hydroperoxide metabolism in mammalian organs. Physiol. Rev. 59, 527-605.

Davies, K.J.A., 1987. Protein damage and degradation by oxygen radicals. J. Biol. Chem. 262, 9895-9901.

de Grey, A.D.N.J., 2002. $\mathrm{HO}_{2}{ }^{*}$ : The forgotten radical. DNA CELL Biol. 21, 251-257.

de Haan, J.B., Cristiano, F., Jannello, R.C., Kola, I., 1995. Cu/Znsuperoxide dismutase and glutathione peroxidase during aging. Biochem. Mol. Biol. Int. 35, 1281-1297.

Fleming, J.E., Leon, H.A., Miquel, J., 1981. Effects of ethidium bromide on development and aging of Drosophila: Implications for the free radical theory of aging. Exp. Gerontol. 16, 287-293.

Fridovich, I., 1978. The biology of oxygen radicals. Science 201, $875-880$.

Gardner, R., Salvador, A., Moradas-Ferreira, P., 2002. Why does SOD overexpression sometimes enhance, sometimes decrease, hydrogen peroxide production? A minimalist explanation. Free Rad. Biol. Med. 32, 1351-1357.

Goss, S.P.A., Singh, R.J., Kalyanaraman, B., 1999. Bicarbonate enhances the peroxidase activity of $\mathrm{Cu}, \mathrm{Zn}$-superoxide dismutase. J. Biol. Chem. 274, 28233-28239
Groner, Y., Elroy-Stein, O., Bernstein, Y., Dafni, N., Levanon, D., Danciger, E., Neer, A., 1986. Molecular genetics of Down's syndrome: overexpression of transfected human $\mathrm{Cu} / \mathrm{Zn}$-superoxide dismutase gene and the consequent physiological changes. Cold Spring Harbor Symp. Quant. Biol. LI, 381-393.

Groner, Y., Elroy-Stein, O., Avraham, K.B., Yarom, R., Schickler, M., Knobler, H., Rotman, G., 1990. Down syndrome clinical symptoms are manifested in transfected cells and transgenic mice overexpressing the human $\mathrm{Cu} / \mathrm{Zn}$-superoxide dismutase gene. J. Physiol., Paris 84, 53-77.

Halliwell, B., Gutteridge, J.M.C., 1989. Free Radicals in Biology and Medicine, second ed. Oxford University Press, New York.

Halliwell, B., Gutteridge, J.M.C., 1999. Free Radicals in Biology and Medicine, third ed. Oxford University Press, New York.

Harman, D., 1956. A theory based on free radical and radiation chemistry. J. Gerontol. 11, 298-300.

Harman, D., 1981. The aging process. Proc. Natl. Acad. Sci. (USA) 78, 7124-7128.

Hodgson, E.K., Fridovich, I., 1975. The interaction of bovine erythrocyte superoxide dismutase with hydrogen peroxide: chemiluminescence and peroxidation. Biochemistry 14, 5299-5303.

Joenje, H., 1989. Genetic toxicology of oxygen. Mutat. Res. 219, 193-208.

Joenje, H., Gille, J.J.P., Oostra, A.B., van der Valk, P., 1985. Some characteristics of hyperoxia-adapted HeLa cells. Lab. Invest. 52, 420-428.

Kelner, M.J., Bagnell, R., 1990. Alteration of endogenous glutathione peroxidase, manganese superoxide dismutase, and glutathione transferase activity in cells transfected with a copper-zinc superoxide dismutase expression vector. J. Biol. Chem. 265, 10872-10875.

Keller, J.N., Kindy, M.S., Holtsberg, F.W., St Clair, D.K., Yen, H.C., Germeyer, A., Steiner, S.M., Bruce-Keller, A.J., Hutchins, J.B., Mattson, M.P., 1998. Mitochondrial manganese superoxide dismutase prevents neural apoptosis and reduces ischemic brain injury: suppression of peroxynitrite production, lipid peroxidation, and mitochondrial dysfunction. J. Neurosci. 18, 687-697.

Liochev, S.I., Fridovich, I., 2000. Copper and zinc-containing superoxide dismutase can act as a superoxide reductase and a superoxide oxidase. J. Biol. Chem. 275, 38482-38485

Mao, G.D., Panakkezhum, D.T., Lopaschuk, G.D., Poznansky, M.J., 1993. Superoxide dismutase (SOD)-catalase conjugates. Role of hydrogen peroxide and the fenten reaction in SOD toxicity. J. Biol. Chem. 268, 416-420.

McCord, J.M., Fridovich, I., 1969. Superoxide dismutase. An enzymic function for erythrocuprein (hemocuprein). J. Biol. Chem. 244, 6049-6055.

Meneghini, R., 1988. Genotoxicity of active oxygen species in mammalian cells. Mutation Research 195, 215-230.

Minc-Golomb, D., Knobler, H., Groner, Y., 1991. Gene dosage of CuZnSOD and Down's syndrome: diminished prostaglandin synthesis in human trisomy 21 , transfected cells and transgenic mice. EMBO J. 10, 2119-2124.

Nelson, S.K., Bose, S.K., McCord, J.M., 1994. The toxicity of highdose superoxide dismutase suggests that superoxide can both initiate and terminate lipid peroxidation in the reperfused heart. Free Rad. Biol. Med. 16, 195-200.

Offer, T., Russo, A., Samuni, A., 2000. The pro-oxidative activity of SOD and nitroxide SOD mimics. FASEB J. 14, 1215-1223.

Omar, B.A., McCord, J.M., 1990. The cardioprotective effect of Mnsuperoxide dismutase is lost at high doses in the postischemic isolated rabbit heart. Free Rad. Biol. Med. 9, 473-478.

Orr, W.C., Sohal, R.S., 1993. Effects of $\mathrm{Cu}-\mathrm{Zn}$ superoxide dismutase overexptression on life span and resistance to oxidative stress in transgenic Drosophila melanogaster. Arch. Biochem. Biophys. 301, 34-40. 
Palenik, B., Brahamsha, B., Larimer, F.W., Land, M., Hauser, L., Chain, P., Lamerdin, J., Regala, W., Allen, E.E., McCarren, J., Paulsen, I., Dufresne, A., Partensky, F., Webb, E.A., Waterbury, J., 2003. The genome of a motile marine Synechococcus. Nature 424, 1037-1042.

Pryor, W.A., 1973. Free radical reactions and their importance in biochemical systems. Fed. Proc. 32, 1862-1869.

Reveillaud, I., Niedzwiecki, A., Bensch, K.G., Fleming, J.E., 1991. Expression of bovine superoxide dismutase in Drosophila melanogaster augments resistance to oxidative stress. Mol. Cell. Biol. 11, $632-640$.

Sankarapandi, S., Zweier, J.L., 1999. Bicarbonate is required for the peroxidase function of $\mathrm{Cu}, \mathrm{Zn}$-Superoxide dismutase at physiological pH. J. Biol. Chem. 274, 1226-1232.

Schickler, M., Knobler, H., Avraham, K.B., Elroy-Stein, O., Groner, Y., 1989. Diminished serotonin uptake in platelets of transgenic mice with increased $\mathrm{Cu} / \mathrm{Zn}$-superoxide dismutase activity. EMBO J. 8, 1385-1392.

Schwartz, P.J., Coyle, J.T., 1998. Effects of overexpression of the cytoplasmic copper-zinc superoxide dismutase on the survival of neurons in vitro. Synapse 29, 206-212.

Scott, M.D., Meshnick, S.R., Eaton, J.W., 1987. Superoxide dismutase rich bacteria. Paradoxidal increase in oxidant toxicity. J. Biol. Chem. 262, 3640-3645.

Seto, N.O.L., Hayashi, S., Tener, G.M., 1990. Overexpression of $\mathrm{Cu}-\mathrm{Zn}$ superoxide dismutase in Drosophila does not affect lifespan. Proc. Natl. Acad. Sci. (USA) 87, 4270-4274.
Sinet, P.M., 1982. Metabolism of oxygen derivatives in down's syndrome. Ann. NY Acad. Sci. 396, 83-94.

Siwecki, G., Brown, O.R., 1990. Biochem. Int. 20, 191-200.

Tyler, D.D., 1975. Polarographic assay and intracellular distribution of superoxide dismutase in rat liver. Biochem. J. 147, 493-504.

Wolff, S.P., Garner, A., Dean, R.T., 1986. Free radicals, lipids and protein degradation. Trends Biochem. Sci. 11, 27-31.

Yarom, R., Sapoznikov, D., Havivi, Y., Avraham, K.B., Schickler, M., Groner, Y., 1988. Premature aging changes in neuromuscular junctions of transgenic mice with an extra human CuZnSOD gene: a model for tongue pathology in Down's syndrome. J. Neurol. Sci. $88,41-53$.

Yim, M.B., Chock, P.B., Stadtman, E.R., 1990. Copper, zinc superoxide dismutase catalyzes hydroxyl radical production from hydrogen peroxide. Proc. Natl. Acad. Sci. (USA) 87, 5006-5010.

Yim, M.B., Chock, P.B., Stadtman, E.R., 1993. Enzyme function of copper, zinc superoxide dismutase as a free radical generator. J. Biol. Chem. 268, 4099-4105.

Youn, H.D., Kim, E.J., Roe, J.H., Hah, Y.C., Kang, S.O., 1996. A novel nickel-containing superoxide dismutase from Streptomyces spp. Biochem. J. 318, 889-896.

Zhong, W.X., Oberley, L.W., Oberley, T.D., Yan, T., Domann, F.E., StClair, D.K., 1996. Inhibition of cell-growth and sensitization to oxidative damage by overexpression of manganese superoxidedismutase in rat glioma cells. Cell Growth Differentiation 7, $1175-1186$ 